\title{
A higher fat free mass percentage is associated with better physical performance in overweight and obese older adults
}

\author{
Author(s) \\ Miguel, T.S.; de Groot, K.S.; Verreijen, A.M.; Engberink, M.F.; Weijs, P.J.M. \\ DOI
}

10.1016/S0261-5614(16)30845-7

Publication date

2016

Document Version

Final published version

Link to publication

Citation for published version (APA):

Miguel, T. S., de Groot, K. S., Verreijen, A. M., Engberink, M. F., \&

Weijs, P. J. M. (2016). A higher fat free mass percentage is associated with better physical performance in overweight and obese older adults. https://doi.org/10.1016/S0261-5614(16)30845-7

It is not permitted to download or to forward/distribute the text or part of it without the consent of the author(s) and/or copyright holder(s), other than for strictly personal, individual use, unless the work is under an open content license (like Creative Commons).

If you believe that digital publication of certain material infringes any of your rights or (privacy) interests,

please let the Library know, stating your reasons. In case of a legitimate complaint, the Library will make the material inaccessible and/or remove it from the website. Please contact the library:

https://www.amsterdamuas.com/library/contact/questions, or send a letter to: University Library (Library of the University of Amsterdam and Amsterdam University of Applied Sciences), Secretariat, Singel 425, 1012 WP Amsterdam, The Netherlands. You will be contacted as soon as possible. 


\section{MON-P211}

A HIGHER FAT FREE MASS PERCENTAGE IS ASSOCIATED WITH BETTER PHYSICAL PERFORMANCE IN OVERWEIGHT AND OBESE OLDER ADULTS

T. S. Miguel ${ }^{1,2}$, K. S. de Groot ${ }^{2}$, A. M. Verreijen ${ }^{2}$, M. F. Engberink ${ }^{2}$, R. G. Memelink ${ }^{2}$, P. J. Weijs ${ }^{2,3}$. ${ }^{1}$ University CEU-San Pablo, Madrid, Spain; ${ }^{2}$ Department of Nutrition and Dietetics, Faculty of Sports and Nutrition, Amsterdam University of Applied Sciences, ${ }^{3} \mathrm{VU}$ University Medical Center, Amsterdam, Netherlands

Rationale: Obesity worsens the age related decline in physical performance. A high BMI however is not only related to a higher fat mass (FM), but also to a higher fat free mass (FFM). For dietetic treatment it is relevant to know how body composition (FFM\%) is related to physical performance in the growing population of older overweight and obese adults.

Methods: We included 246 overweight and obese adults (55$80 \mathrm{y}$ ) in a cross-sectional analysis and studied the association between FFM\% and physical performance (handgrip strength (HGS), $4 \mathrm{~m}$ gait speed (4 mGS), $400 \mathrm{mGS}$ and time to perform 5 chair stands (CS)). FFM and FM were measured by air displacement plethysmography. Linear regression analysis was performed with determinant FFM\% and physical performance measures as outcome variables. Adjustments were made for age (and height for CS). Because age was an effect modifier for HGS and 4 mGS, analyses were stratified for age (younger: 5565 y vs older: $66-80$ y).

Results: Mean age of the subjects was $64 \pm 5$ y with a BMI of $33 \pm$ $5 \mathrm{~kg} / \mathrm{m}^{2}$ and $43 \%$ were men. FFM\% was significantly associated with all physical performance measures. For all subjects an increase of $1 \%$ in FFM was associated with $+1.6 \mathrm{~kg} \mathrm{HGS}$, $+0.01 \mathrm{~m} / \mathrm{s} 4 \mathrm{mGS},+0.01 \mathrm{~m} / \mathrm{s} 400 \mathrm{mGS}$ and $-0.1 \mathrm{~s}$ CS (all: $\mathrm{p}<$ $0.01)$. An increase of $1 \%$ in FFM was associated with $\mathrm{a}+2.0 \mathrm{~kg}$ for HGS $(p<0.01)$ and $+0.02 \mathrm{~m} / \mathrm{s}$ for $4 \mathrm{mGS}(p<0.01)$ in the older subjects. In the younger, associations of $+1.5 \mathrm{~kg}$ $(p<0.01)$ and $+0.01 \mathrm{~m} / \mathrm{s}(\mathrm{p}=0.02)$ were shown.

Conclusion: A higher FFM\% is significantly associated with better HGS, 4 mGS, 400 mGS and CS in older obese adults. These findings support that weight loss treatment should focus on FFM preservation and FM loss in overweight and obese older adults.

Disclosure of Interest: None declared

\section{MON-P212 \\ PREDICTIVE VALUE FOR METABOLIC SYNDROME OF \\ ANTHROPOMETRIC AND CALCULATED SURROGATE MARKERS OF VISCERAL FAT IN AN OVERWEIGHT POPULATION COHORT}

R. Barazzoni ${ }^{1}$, G. Gortan Cappellari ${ }^{1}$, A. Semolic ${ }^{1}$, M. Ius ${ }^{1}$, G. Pivetti ${ }^{1}$, M. Zanetti ${ }^{1}$, P. Vinci ${ }^{1}$, G. Guarnieri ${ }^{1}$. ${ }^{1}$ Medical, Surgical and Health Sciences, University of Trieste,

Trieste, Italy

Rationale: In overweight and obesity, central fat distribution (CF) enhances the risk for metabolic complications commonly clustered in the metabolic syndrome (MetS). Direct CF measurement is however not routinely feasible, and surrogate anthropometric markers including waist circumference (WC) are used to identify individuals at higher metabolic risk. More recently, the visceral adiposity index (VAI) and a body shape index (ABSI) have been proposed as calculated CF markers combining WC and biochemical parameters, but their ability to identify the risk of developing MetS in overweight individuals remains undetermined.

Methods: We investigated associations between MetS (ATPIII diagnostic criteria) and WC, VAI or ABSI in an overweight population from the North-East Italy MoMa epidemiological study $\left(n=1140\right.$, age $\left.=53 \mathrm{y}, M / F=635 / 505, B M I=31.4 \mathrm{~kg} / \mathrm{m}^{2}\right) . A$ representative patient subgroup $(n=271$; age $=54, M / F=142$ / $129, \mathrm{BMI}=30.7$ ) was further evaluated at 5-year follow-up.

Results: In all subjects WC, VAI and ABSI were associated positively with MetS and after adjustment for sex, age and metabolic confounders $(p<0.0001)$. Basal WC and VAl also predicted MetS at 5-year follow-up after multiple adjustments $(p<0.0001 ; r=0.31-0.44)$. In contrast, no predictive value for 5 -year MetS was observed for basal ABSI $(r=0.09, p=N S)$. Individuals free of MetS at baseline who developed MetS over the 5-year follow-up ( $n=26)$ accordingly had higher basal WC and VAI but similar basal ABSI compared to those who remained MetS-free $(p<0.01)$.

Conclusion: In a North-East Italy overweight population, WC and VAl comparably predict development of MetS over a 5-year period. No predictive value is observed for ABSI. The current findings do not support the use of recently-proposed calculated surrogate CF markers over WC to assess the risk of metabolic syndrome in overweight-obese individuals.

Disclosure of Interest: None declared

\section{MON-P213}

THE EFFECT OF OVERWEIGHT AND OBESITY ON WEIGHT LOSS AND LENGTH OF STAY IN PATIENTS WITH WALLED-OFF PANCREATIC NECROSIS

S. Rysgaard ${ }^{1}$, E. Hermansen ${ }^{1}$, D. Rasmussen ${ }^{1}$, S. Novovic ${ }^{1}$, P. N. Schmidt ${ }^{1}$, L. L. Gluud ${ }^{1}$. ${ }^{1}$ Department of Gastroenterology and Gastrointestinal Surgery, Hvidovre Hospital, Hvidovre, Denmark

Rationale: To assess the importance of overweight and obesity on weight loss and length of stay in patients with walled-off pancreatic necrosis.

Methods: Retrospective cohort study including 38 patients with walled-off pancreatic necrosis.

Results: All patients were categorized as being in high risk of undernutrition at admission. At admission, 23 patients (61\%) had a BMI $\geq 25$ (overweight) and seven (18\%) a BMI $\geq 30$ (obese). Remaining patients were normal-weight; none were underweight. Compared to patients classified as normal weight, the weight loss during admission was more than twice as high for patients with overweight (4\% versus $9 \% ; p<0.01)$ and the weight loss was three times as high for patients with obesity $(4 \%$ versus $14 \% ; p<0.01)$. The energy and protein coverage were associated with a greater weight loss. The length of stay was longer for patients with overweight (Log rank $p=0.02)$. Regardless of the energy or protein coverage or length of stay, overweight and obesity predicted a greater weight loss in multivariable regression analysis $(p<0.01)$.

Conclusion: Patients with walled-off pancreatic necrosis have a considerable risk of malnutrition/undernutrition. A BMI $\geq 25$ predicts greater weight loss and longer length of stay.

Disclosure of Interest: None declared 